\title{
Backcalculated Modulus of Asphalt Concrete
}

\author{
Md Rashadul Islam ${ }^{1 *}$, Rafiqul Tarefder ${ }^{2}$, Mesbah U. Ahmed ${ }^{3}$ \\ 1. Colorado State University-Pueblo, 2200 Bonforte Blvd, Pueblo, CO 81001, USA \\ 2. University of New Mexico, MSC 01 1070, 1 University of New Mexico, Albuquerque, NM 87106, USA \\ 3. Gemini Technologies Inc., 3153 Fire Rd. Egg Harbor Township, NJ, 08234, USA \\ *E-mail:md.islam@csupueblo.edu (Corresponding author)
}

Received: 13 July 2019; Accepted: 23 August 2019; Available online: 30 September 2019

\begin{abstract}
Asphalt Concrete (AC) is considered a spatially homogeneous material when analyzing and designing asphalt pavement. However, the modulus of AC along the wheel path and the middle of the wheel path may not be the same considering the continuous compaction by wheel loading. This study conducted monthly Falling Weight Deflectometer (FWD) tests to determine the AC modulus of a pavement section on Interstate 40 (I-40) in the state of New Mexico, USA from 2013 to 2015. The AC moduli on the wheel path, on the middle of the wheel path, on the shoulder with friction course, and on the shoulder without friction course are determined. It is mentionable that the driving lane and the shoulder have the same geometry, materials, and compaction effort. Results show that the modulus along the wheel path is almost the same as that of along the middle of the wheel path. The shoulder without friction course has a modulus greater than that of the lane AC modulus and the shoulder with the friction course. In addition, FWD backcalculated moduli at different temperatures are compared with the dynamic modulus values of the AC layer. It is found that the dynamic modulus at a loading frequency of $5 \mathrm{~Hz}$ is 1.7 to 1.9 times the backcalculated AC modulus.
\end{abstract}

Keywords: Asphalt pavement; Falling weight deflectometer test; Dynamic modulus; Spatial variations; Seasonal variations.

\section{Introduction}

Falling Weight Deflectometer (FWD) is a nondestructive test to measure the pavement surface deflection by applying a predefined load. In this test, an impulse load is dropped on the surface using mechanical loading system. In response to the applied load, the pavement surface deflects downward forming a deflection basin. FWD testing and the corresponding surface deflection schematic are shown in Figure. 1. Sensors (geo-phones) installed at different offsets from the loading point measure these vertical deflections. The FWD device can accommodate seven to nine sensors for the measurement of vertical deflections. However, in this study seven geophones are used at different radial offsets from the load. The distances of the geophones from the center of the loading plate are 0 $\mathrm{mm}, 200 \mathrm{~mm}, 300 \mathrm{~mm}, 450 \mathrm{~mm}, 600 \mathrm{~mm}, 900 \mathrm{~mm}$, and $1.5 \mathrm{~m}$. The sensor at $0 \mathrm{~mm}$ distance signifies the surface deflection at the loading point. The magnitudes are typically varied at three load levels of 9, 12, and 16 kips.

Backcalculation of the layer moduli is the interpretation of the pavement strength condition from the FWD test data. Therefore, it also involves some layer properties of the pavement to carry out the analysis. The layer properties cover the layer number and thicknesses, the initially assumed modulus of elasticity and Poisson's ratio of each layer material, and the pavement surface temperature. The reverse processes of the determining the layer moduli from the FWD data as well as the pavement layer properties are the basic tasks of the backcalculation software. Briefly, the applied load, resulting deformation, layer thickness, layer type, temperature, etc., are provided in the input window. After backcalculating, the layer modulus are obtained as output. The layer modulus determined from the FWD data is termed as backcalculated modulus.

The modulus of the material is determined using the load and deflection data with the available mechanistic analysis. Multi-layered elastic analysis is used in the current study as pavement is a multi-layered system. The details of the numerical simulation procedure of multi-layered elastic method is available in the study by Ahmed [1]. The application of the multi-layered elastic method is simple and fast in the computation of pavement response. However, it has some limitations in representing the true behavior of the field situation. For example, the analysis uses sharp layer discretion, full bonding between layers, homogenous elastic materials, etc., although, these behaviors are not fully valid for real pavement. In this theory, all the layers are horizontally infinite; that is not possible in any pavement section. A number of software products are available for the analysis of FWD data to obtain backcalculated layer modulus such as ELMOD, BAKFAA, EVERCALC, MODULUS, etc. ELMOD is 
used in the current study for its high speed, capacity and user friedliness [1]. Several factors affect the output of backcalcualtion such as loading value, temperature, boundary conditions, and so on. While analyzing, these values should be properly assigned for accurate results. Another issue of backcalculated modulus is that the result may be a little skewed from the accurate value [1]. However, for comparison purposes, this limilation does not exist. The backcalculated modulus is very important in pavement sector as it is not only used in design but also to determine the remaining life of the pavement, thus, the role of this layer modulus is significant in pavement engineering [2-3].

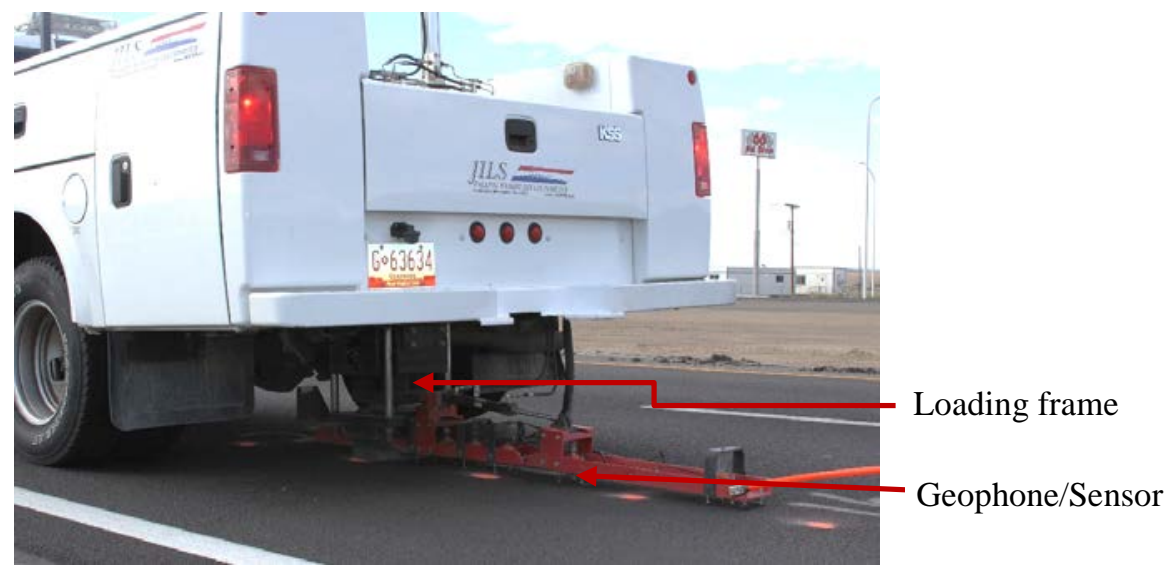

a) FWD testing assembly

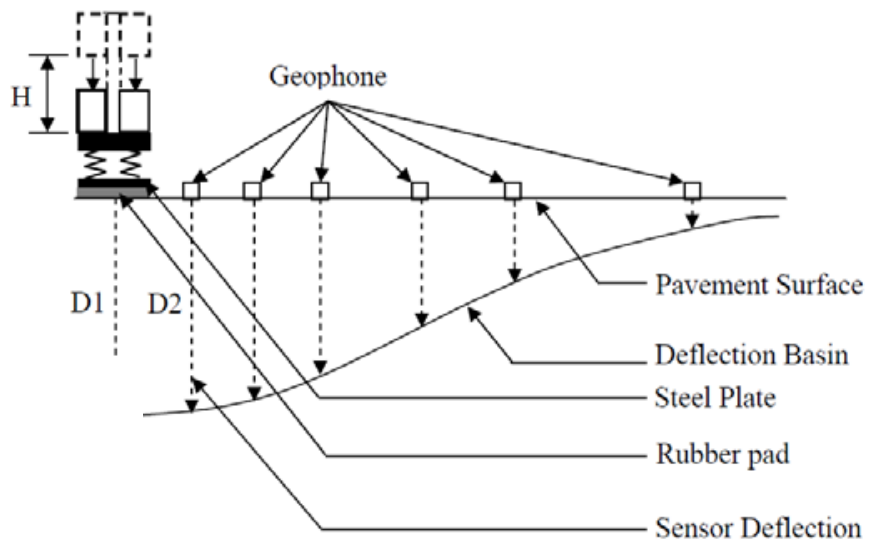

b) Schematic deflection basin of pavement surface

Figure 1. FWD test and the pavement surface response.

The FWD test has been conducted by numerous researchers for various reasons. Orr [4] conducted FWD tests measuring in situ modulus of pavement material at various seasons in order to monitor the seasonal variations of Asphalt Concrete (AC) modulus in four sites in New York. The variations of FWD modulus with frost depth and temperature were specifically investigated. FWD tests were also conducted to evaluate the stress-strain response in the instrumentation section. For example, Islam et al. [5] conducted FWD tests to evaluate the functionality of installed stress-strain measuring sensors in a pavement section in New Mexico. Appea [6] studied the spatial and temporal variability of the FWD deflections in an instrumentation section in Virginia. He also developed a temperature correction model for the backcalculated AC resilient moduli and compared the backcalculated and laboratory measured resilient moduli. Additionally, the resilient modulus of unbound layers was studied. However, spatial variation of asphalt modulus, decrease in asphalt modulus, correlation laboratory dynamic modulus with backcalculation modulus, etc., were out of scope of the study. Appea found a distinct difference between the laboratory modulus and backcalculated modulus. Shalaby et al. [7] found that laboratory modulus values were considerably lower than FWD backcalculated values. On the other hand, Oh et al. [8] found good correlation between the AC moduli determined from laboratory and field tests at corresponding load frequencies (ranging from 14.2 to $20 \mathrm{~Hz}$ ) and temperatures. They conducted the FWD tests to develop correlations between FWD and laboratory modulus. The above two studies found a contradictory relationship between laboratory modulus and 
backcalculated modulus. Hossain and Scofield [9] also observed similar observation at $0.3 \mathrm{~Hz}$ and $1.0 \mathrm{~Hz}$ of loading.

Birgisson et al. [10] conducted FWD tests along the wheel path and along the middle of the wheel path in a pavement section in Florida. The asphalt layer was $113 \mathrm{~mm}$ thick with a $20 \mathrm{~mm}$ thick Open Graded Friction Course (OGFC). It was found that the modulus along the wheel path is greater than the modulus along the middle of the wheel path. However, they did not differentiate the modulus change due to the OGFC. Note that OGFC is a highly permeable mixture used as a surface coat mainly for removing hydroplaning and improving visibility by reducing glare from standing water on pavement.

Williams and Shaidur [11] conducted FWD tests to determine the structural condition of pavements with and without top-down cracks. The outputs of two backcalculation software were also compared. However, this study also did not investigate the spatial variation of asphalt modulus, the decrease in asphalt modulus, and the correlation laboratory dynamic modulus with the backcalculation modulus, etc. Von Quintus and Simpson [12] analyzed Long Term Pavement Performance (LTPP) in pavement sections to determine the spatial variations of asphalt modulus. They found no significant difference between the computed modulus along the middle of wheel path and along the wheel path measurement locations for a few sections, although other sections showed a significant difference. Therefore, discrete conclusions cannot be made from this study regarding the spatial variations of backcalculated modulus.

The above literature shows that distinct conclusions on spatial variations on backcalculated modulus and the relationship between laboratory modulus and backcalculated modulus are not available. A decrease in asphalt modulus with service life is also unknown. In addition, the change in asphalt modulus due to the application of OGFC is still unknown. The current FWD test monitors the variation of the AC modulus spatially. This study also examines the changes in AC modulus due to the presence of OGFC. In addition, the change of the AC modulus for both the shoulder and wheel path with time is also discussed. This study also investigates the effect of OGFC in the backcalculated modulus of the AC layer.

\section{Objectives}

The objectives of the current study are mentioned below:

a) Determination of the spatial variation of the AC modulus. More clearly, the AC modulus on the wheel path, middle of the wheel path, the shoulder with OGFC and the shoulder without OGFC.

b) Determination of the change in AC modulus with the age of the pavement. This objective includes the AC modulus in both of the wheel path and shoulder.

c) Comparison of the FWD AC modulus with the laboratory determined complex modulus.

\section{Falling weight deflectometer test}

The test section is located on Interstate 40 (I-40) east bound lane at mile post 141 near the city of Albuquerque in New Mexico, USA. It has two lanes; there is a shoulder on both sides. The test was only conducted in the driving lane and on the shoulder. Figure. 2 shows the geometry of the pavement section used in the current study. It has four layers: surface layer of AC (263 mm), granular base $(150 \mathrm{~mm})$, granular subbase $(200 \mathrm{~mm})$, and the subgrade. There is a $12.5 \mathrm{~mm}$ thick OGFC layer on the top of AC layer. This OGFC layer was applied on the driving lane, passing lane and some part of the shoulder. Therefore, some part of the shoulder has no OGFC. The terminology "Wheel Path" means the centerline of the wheel; "Middle of Wheel Path" means the middle of the lane as wheel loading is unusual along the middle of the wheel path.

The AC mix contained 35\% Recycled Asphalt Pavement (RAP) materials. Performance Grade (PG) binder PG 76-22 (design binder) was used $4.4 \%$ by the weight of the mixture. The virgin binder was PG 70-22. Three types of aggregates with the Nominal Maximum Aggregate Size (NMAS) of $22 \mathrm{~mm}, 16 \mathrm{~mm}, 9 \mathrm{~mm}$ and two types of fines, crusher fines and natural sand were used with the percentage mentioned. A total of 35\% RAP was used with an equal percentage from the West Central and Budhagers milling sites near the city of Albuquerque in New Mexico. The Bulk Specific Gravity $\left(G_{m b}\right)$ of the individual component varied between 2.571 and 2.868. The nominal maximum aggregate sizes for AC and OGFC are $19 \mathrm{~mm}$ and $8.75 \mathrm{~mm}$ respectively.

The base course was composed of 50\% of crushed stone aggregate and 50\% of screened RAP materials milled from the site. The subbase layer had about 75\% RAP and 25\% in-situ subgrade. The RAPs used in the base and subbase were not characterized by the design agency, New Mexico Department of Transportation (NMDOT). The whole pavement (subbase, base, and asphalt) was reconstructed in 2012.

The bulk densities of the field collected cores (without OGFC) were determined using the saturated surface dry sample method following the AASHTO T166-07 [13] standard. The theoretical maximum density of the loose mixture collected while paving was determined by using the AASHTO 209-05 [14] standard. The average air void of the field AC was $4.4 \%$ with a standard deviation of $0.7 \%$. The air void of OGFC was not determined in the 
current study; however, the design air void of OGFC was 14\%. Field air void of AC was measured by the NMDOT using the nuclear density gage. Measuring the air void of OGFC was not the design/construction specification. Finally, NMDOT did not measure the air void of OGFC and thus, it is not exactly known.

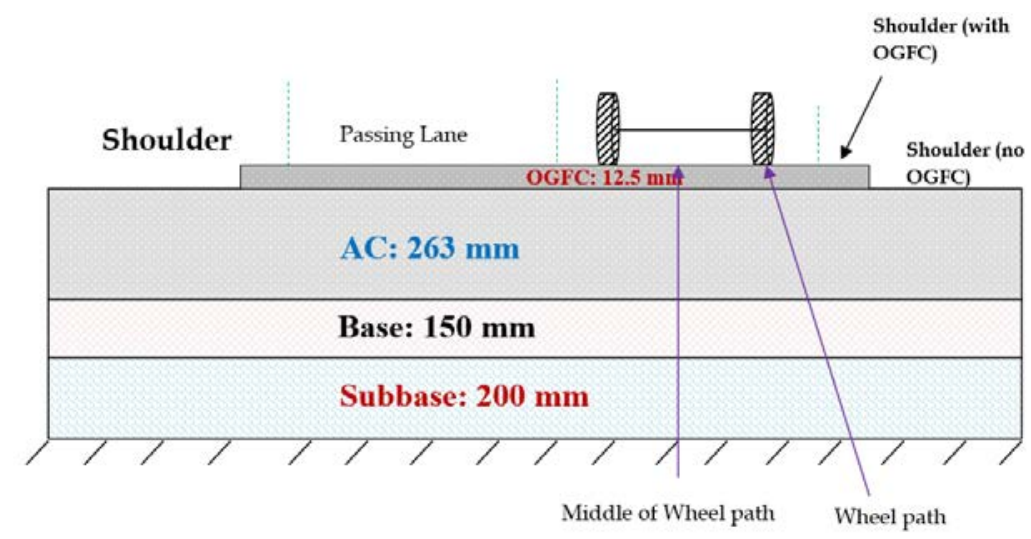

Figure 2. Profile of the instrumentation section.

\section{Installation of temperature probes}

The AC temperatures were measured at four different depths using the installed temperature probes at different depths. The average AC temperature was calculated using the temperatures from these four probes. The installation of temperature probes are shown in Figure. 3. The depths are the surface, $50 \mathrm{~mm}, 100 \mathrm{~mm}$, and $263 \mathrm{~mm}$ from the surface. The average temperature was measured as the arithmetic mean value from the four measurements.

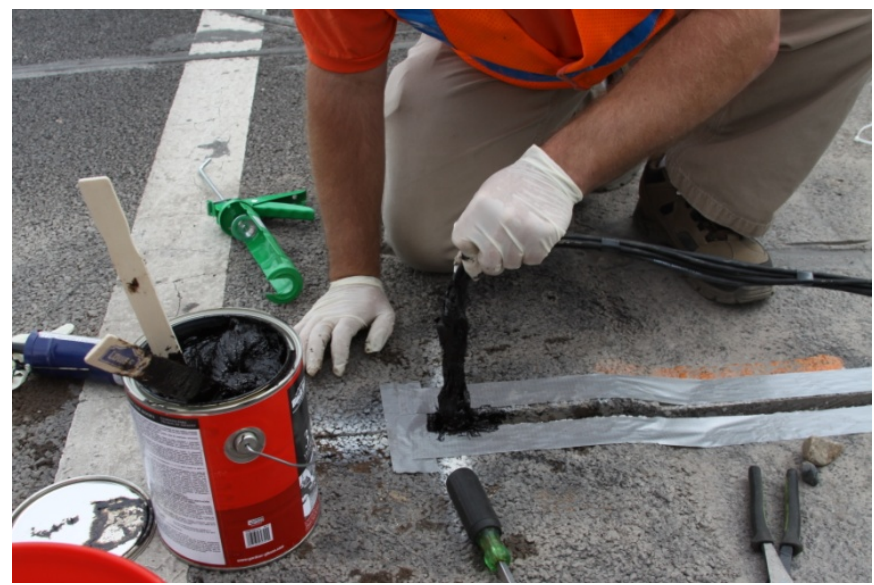

Figure 3. Installation of temperature probes.

\section{FWD testing}

The FWD testing commenced in February 2013 and continued up to May 2015, once in a month (typically, the first week), every hour from 9 am to $3 \mathrm{pm}$. There were a few months when the test could not be conducted because of traffic control issues. A total of twenty points were selected, which are schematically shown in Figure. 4:

a) 9 points along the wheel path

b) 2 points along the middle of the wheel path

c) 4 points on the shoulder with OGFC

d) 5 points on the shoulder without OGFC

A total of 15 drops of loads were applied on each selected point. The 15 drops consisted of 5 drops of 9 kips, 5 drops of 12 kips and 5 drops of 16 kips loading. The resulting deflections were measured at seven different radial points. The test data was processed with the backcalculation software, ELMOD to determine the moduli of materials. The execution of FWD testing on the pavement section is shown in Figure. 5. 


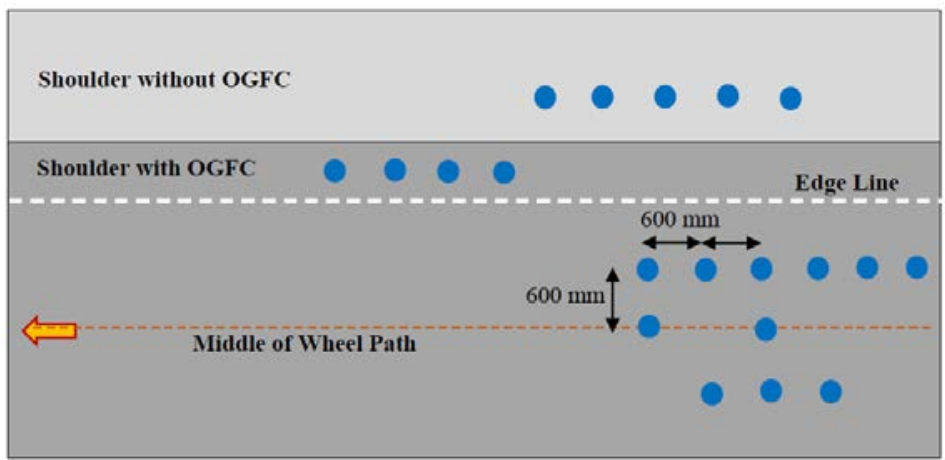

Figure 4. Twenty test points in the $x-y$ plane.

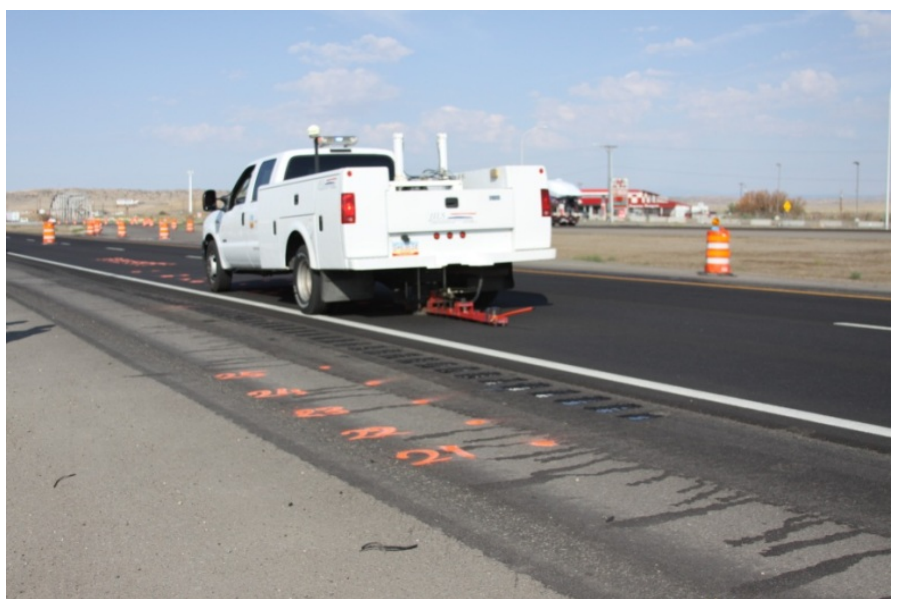

Figure 5. Conduction of FWD test on I-40 pavement.

\section{Results and discussion}

\subsection{Spatial variation in AC modulus}

FWD test was conducted on the wheel path, middle of the wheel path, the shoulder with OGFC and the shoulder without OGFC to examine the spatial variation in backcalculated modulus. Figure. 6 shows the spatial distribution of the AC modulus in January 2014. It shows that the shoulder without OGFC, shoulder with OGFC, wheel path and the middle of wheel path have the AC modulus of $7629 \mathrm{MPa}, 6514 \mathrm{MPa}, 7073 \mathrm{MPa}$ and $7059 \mathrm{MPa}$, respectively. The average AC temperature was $4.59{ }^{\circ} \mathrm{C}$ during the testing. Comparing the moduli of the wheel path and middle of the wheel path, these have almost the equal modulus. Von Quintus and Simpson [12] found similar observation while analyzing the LTPP pavement sections. They found no significant difference between the backcalculated modulus for the wheel path and middle of the wheel path for most of the sections. This may be logical in the sense that vehicle loading does not compact as much; and the pavement was almost new (2.5 years old) at the test time.

Comparing the shoulder moduli, the shoulder with no OGFC has a higher modulus than the wheel path. This is logical in the sense that the presence of OGFC lessens the modulus of the AC. The reason that OGFC has a lower modulus is that OGFC typically has a higher air void (10 to 15\%), although this study did not measure the air void of the OGFC. Having a higher air void and open graded mixture, OGFC deforms more for a certain loading compared to the dense graded AC. Wang et al. [15] also found that OGFC has much less modulus compared to the conventional mixture. They conducted laboratory dynamic modulus tests on three types of OGFC mixtures. It is important to mention that both the wheel path and shoulder have the same geometry, materials and compaction efforts. The modulus of the lane is less than the shoulder without OGFC due to the presence of OGFC. Similarly, the shoulder without OGFC is stiffer than the shoulder with OGFC. This is also because of the absence of less stiff OGFC.

\subsection{Shoulder modulus with age}

The decrease in shoulder modulus (combining both the shoulder with OGFC and the shoulder without OGFC) with the age is presented in Figure. 7. It shows that the modulus of AC decreases from $8759 \mathrm{MPa}\left(\right.$ at $6.54{ }^{\circ} \mathrm{C}$ ) to $8361 \mathrm{MPa}\left(\right.$ at $6.54^{\circ} \mathrm{C}$ ) from December 2013 to December 2014. This means the modulus decreases by $4.5 \%$ in 
one year from December 2013 to December 2014. For the period January 2014 to January 2015, the modulus of AC decreases from $7128 \mathrm{MPa}\left(\right.$ at $4.59{ }^{\circ} \mathrm{C}$ ) to $6872 \mathrm{MPa}\left(\right.$ at $4.66{ }^{\circ} \mathrm{C}$ ) respectively. This means the modulus decreases by $3.6 \%$ in one year from January 2014 to January 2015. Combining both data, it can be said that the shoulder modulus decreases by an average of $4.1 \%$ in one year. The shoulder does not support the traffic load. Therefore, the decrease in the shoulder modulus may be due to the damage due to temperature-induced fatigue, moisture, freeze-thaw, etc.

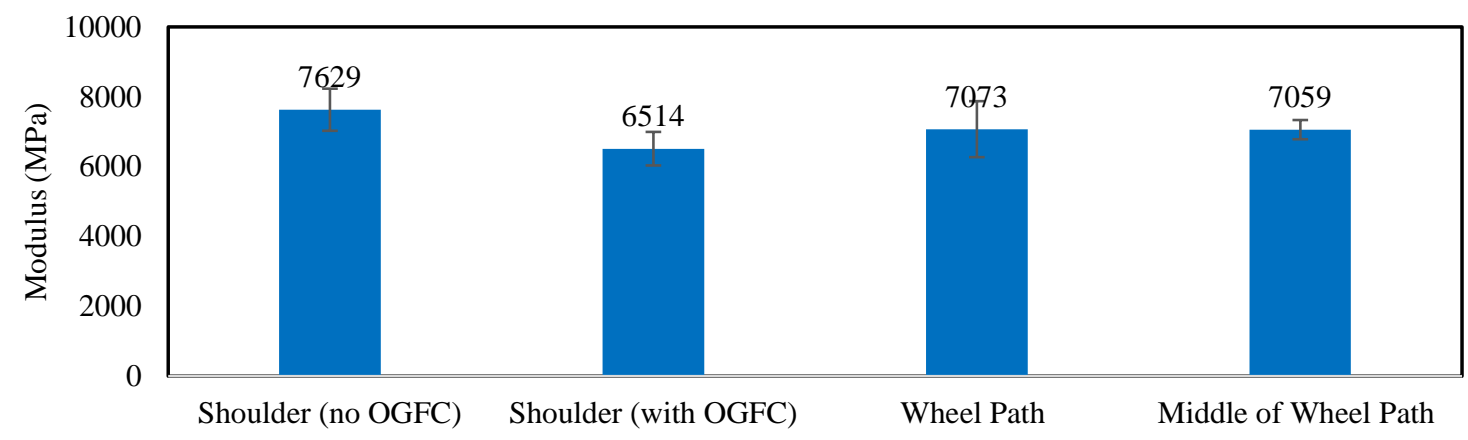

Figure 6. Spatial distribution of AC modulus.

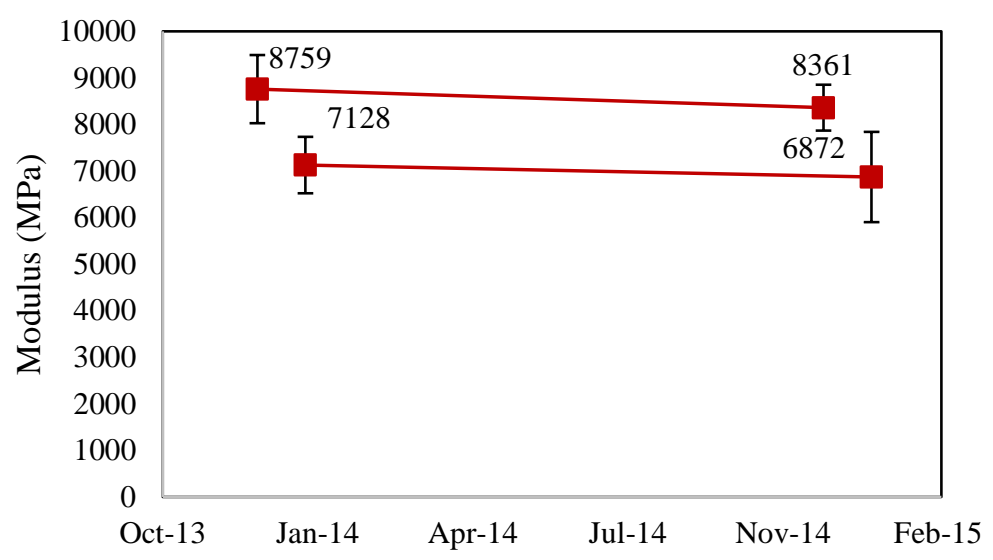

Figure 7. Yearly change in shoulder AC modulus with age.

\subsection{Wheel path modulus with age}

The modulus variation over the service life of the pavement was also investigated. Figure. 8 shows the modulus of the AC along the wheel path with age. It shows that the AC modulus decreases from $8496 \mathrm{MPa}$ to $7563 \mathrm{MPa}$ from December 2013 to December 2014. The average AC temperature was $6.54{ }^{\circ} \mathrm{C}$ during the testing time. Figure. 8 also shows that the AC modulus decreases from 6864 MPa to 4976 MPa from January 2014 to January 2015. The average AC temperature was $4.89{ }^{\circ} \mathrm{C}$ during the testing period. Combining both data, it can be said that the wheel path modulus decreases by an average of $19 \%$ in one year. This means, the AC modulus decreases with time due to traffic related damage and by other environmental factors such as moisture, freeze-thaw, etc.

To examine the seasonal variation of backcalculated modulus, the AC modulus (combining the wheel path and middle of the wheel path) and average AC temperature with age are shown in Figure. 9. It shows that the AC modulus varies from $1890 \mathrm{MPa}$ at $5.5{ }^{\circ} \mathrm{C}$ to $9080 \mathrm{MPa}$ at $40.5{ }^{\circ} \mathrm{C}$ depending on the season. The variation is reasonable as AC modulus increases with the decrease in temperature and vice-versa. Figure. 10 shows the variations of AC modulus with temperature measured on February 5, 2013 and March 12, 2013. AC modulus decreases with an increase in temperature which is also expected. At $4.45^{\circ} \mathrm{C}$, the AC modulus is $7640 \mathrm{Mpa}$, which decreases to $4470 \mathrm{MPa}$ at $20.6^{\circ} \mathrm{C}$. Figure. 10 also shows that the linear best fit curve produces the coefficient of determination $\left(R^{2}\right)$ value of 0.96 , whereas; the exponential relationship produces 0.958 . These values are very close to each other. Therefore, both relationships can be considered appropriate for this temperature range. The reason for this temperature dependent behavior cannot be explained confidently in the current study as it studied a very small temperature range. The authors believe that as the temperature increases, the asphalt binder liquefies, debonds from the aggregates, flows upon loading, and consequently, the modulus of the binder decreases with temperature. Using the linear relationship, it can be found that the AC modulus changes by $184 \mathrm{MPa}$ with a change of AC temperature by $1^{\circ} \mathrm{C}$. This is valid for the pavement studied in the study. Other pavements may have different 
values. For the higher temperature range, the exponential relationship is preferred. The reason is that the straight line assumption may look good for a small segment of a curve. Similar temperature dependent behavior of asphalt was observed by Orr [4], Fernando et al. [16], and Park and Kim [17].

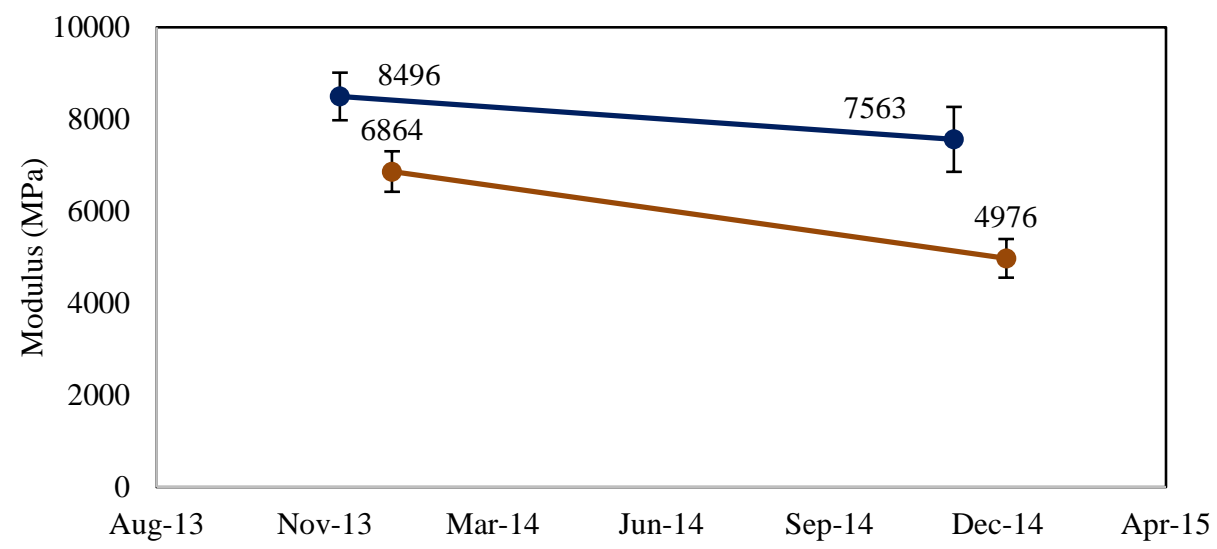

Figure 8. Yearly change in wheel path AC modulus with age.

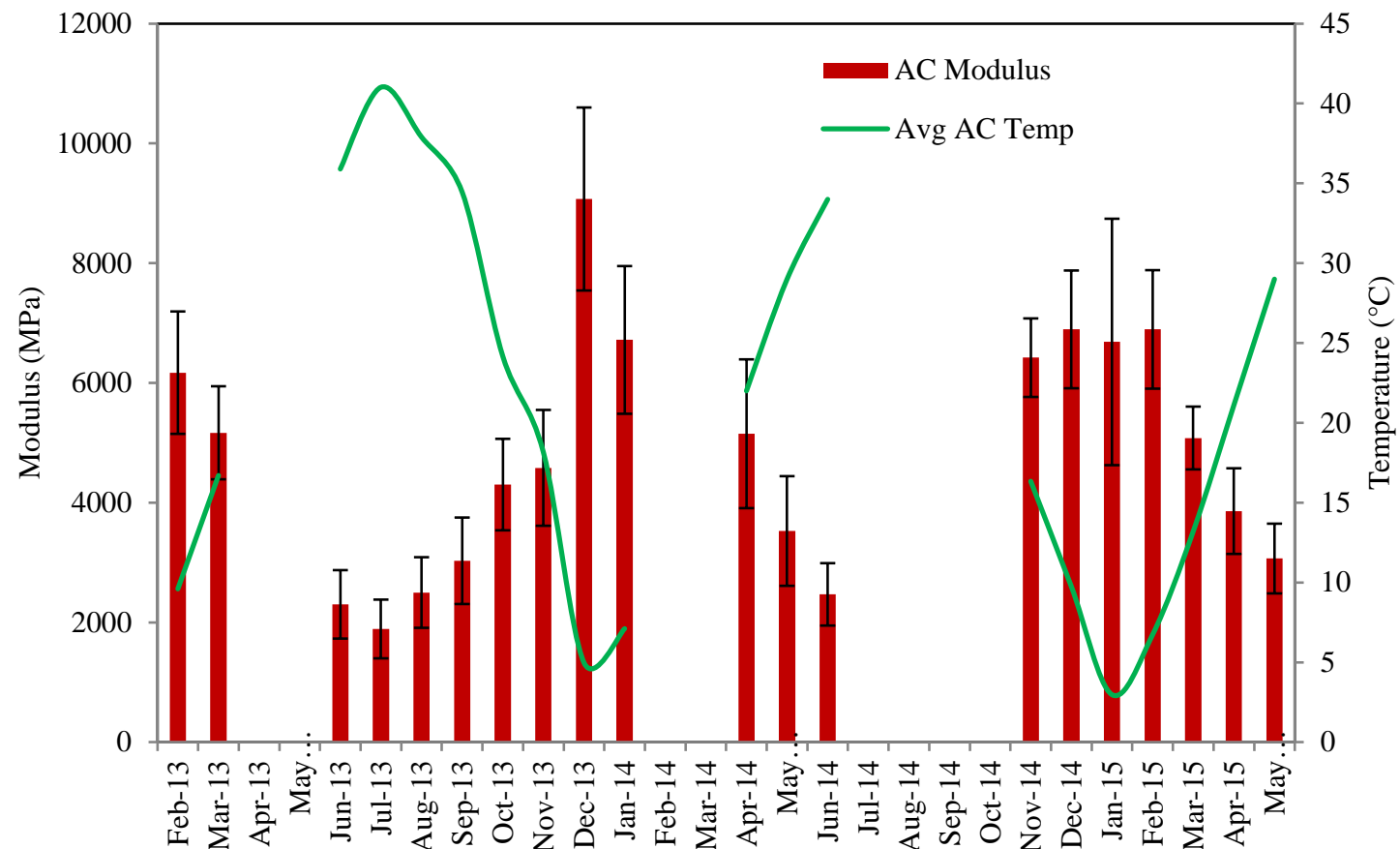

Figure 9. AC modulus with age.

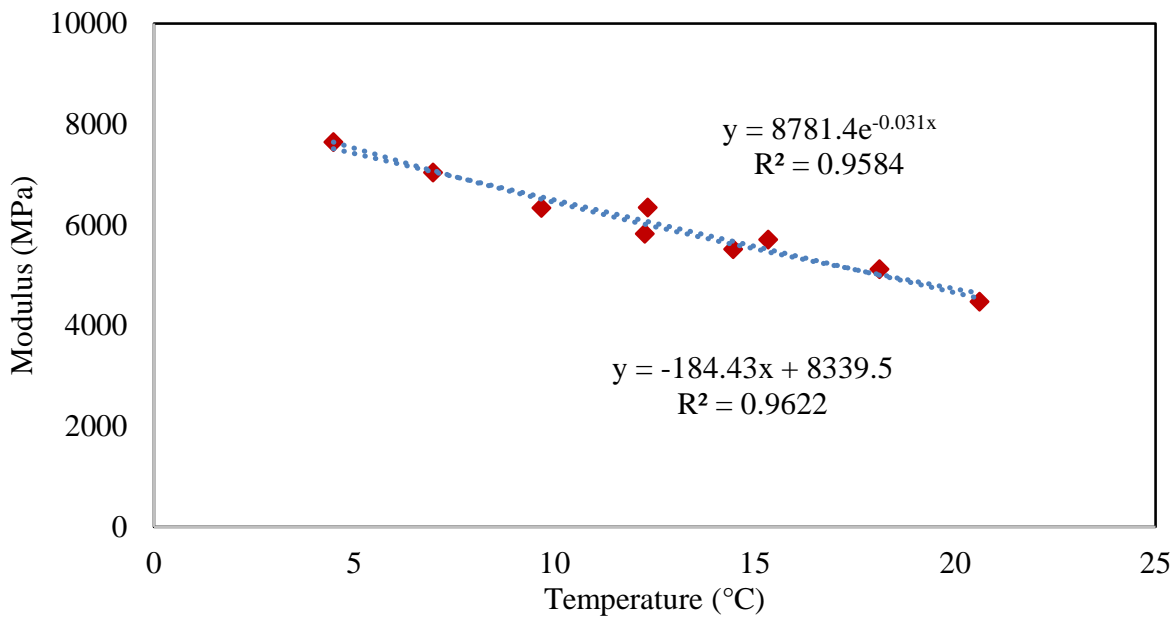

Figure 10. Variation of AC modulus with the average AC temperature. 
A comparison was made between the backcalculated AC modulus and laboratory determined dynamic modulus $\left(\left|E^{*}\right|\right)$. The $\left|E^{*}\right|$ of the same mixture wasdetermined in another study [18]. The test was conducted following the AASHTO PP 62-13 [19] test protocol. The comparative study is based on those results. The $\left|E^{*}\right|$ test was conducted at different temperatures and frequencies of loading. In this step, dynamic modulus at temperatures above $0{ }^{\circ} \mathrm{C}$ were considered since the FWD tests were also conducted above above $0{ }^{\circ} \mathrm{C}$ of pavement surface temperature. Figure. 11 shows the AC moduli using the laboratory test and backcalculated from the FWD test data. It is observed that the dynamic modulus is high at low temperature and vice versa. This trend is similar to the backcalculated AC modulus. The dynamic modulus also increases with an increase in frequency. In case of a FWD test, the load is generally applied with a target loading duration $(t)$ of 0.025 second. According to Ulloa et al. [20], the resulting frequency is $6.4 \mathrm{~Hz}$. The nearest dynamic modulus frequency is $5 \mathrm{~Hz}$. Therefore, the ratio of the dynamic modulus and backcalculated modulus is determined at various temperatures. This modulus ratio varies from 1.7 to 1.9. At lower temperature, up to $21^{\circ} \mathrm{C}$, the backcalcualted AC modulus is close to the laboratory dynamic modulus at 0.1 $\mathrm{Hz}$. At higher temperture of $37^{\circ} \mathrm{C}$, the backcalcualted AC modulus is close to the laboratory dynamic modulus at $0.5 \mathrm{~Hz}$. As discussed earlier, Shalaby et al. [7] found that the laboratory moduli were considerably lower than the FWD backcalculated ones. On the contrary, Oh et al. [8] and Hossain and Scofield [9] found good correlation between the AC moduli determined from laboratory and field tests regardless of the tesing frequency. Therefore, it can be said that the finding on this research topic is not consistent, and hence further research is still required to reach a solid conclusion. However, the difference between the backcalculated modulus and the laboratory dynamic modulus may occur due to several conditions. The temperature variation in the laboratory sample is uniform whereas the temperature variation in the field AC is non-uniform. The field AC is so large compared to the finite laboratory sample. In addition, the samples' boundary conditions, loading type in field and laboratory are quite different. For these stated conditions, there may be a difference between the laboratory modulus and the field modulus. This study, however, cannot explain why the backcalculated modulus at lower temperature is close to the laboratory modulus at $0.1 \mathrm{~Hz}$, and the backcalculated modulus at higher temperature is close to the laboratory modulus at $0.5 \mathrm{~Hz}$.

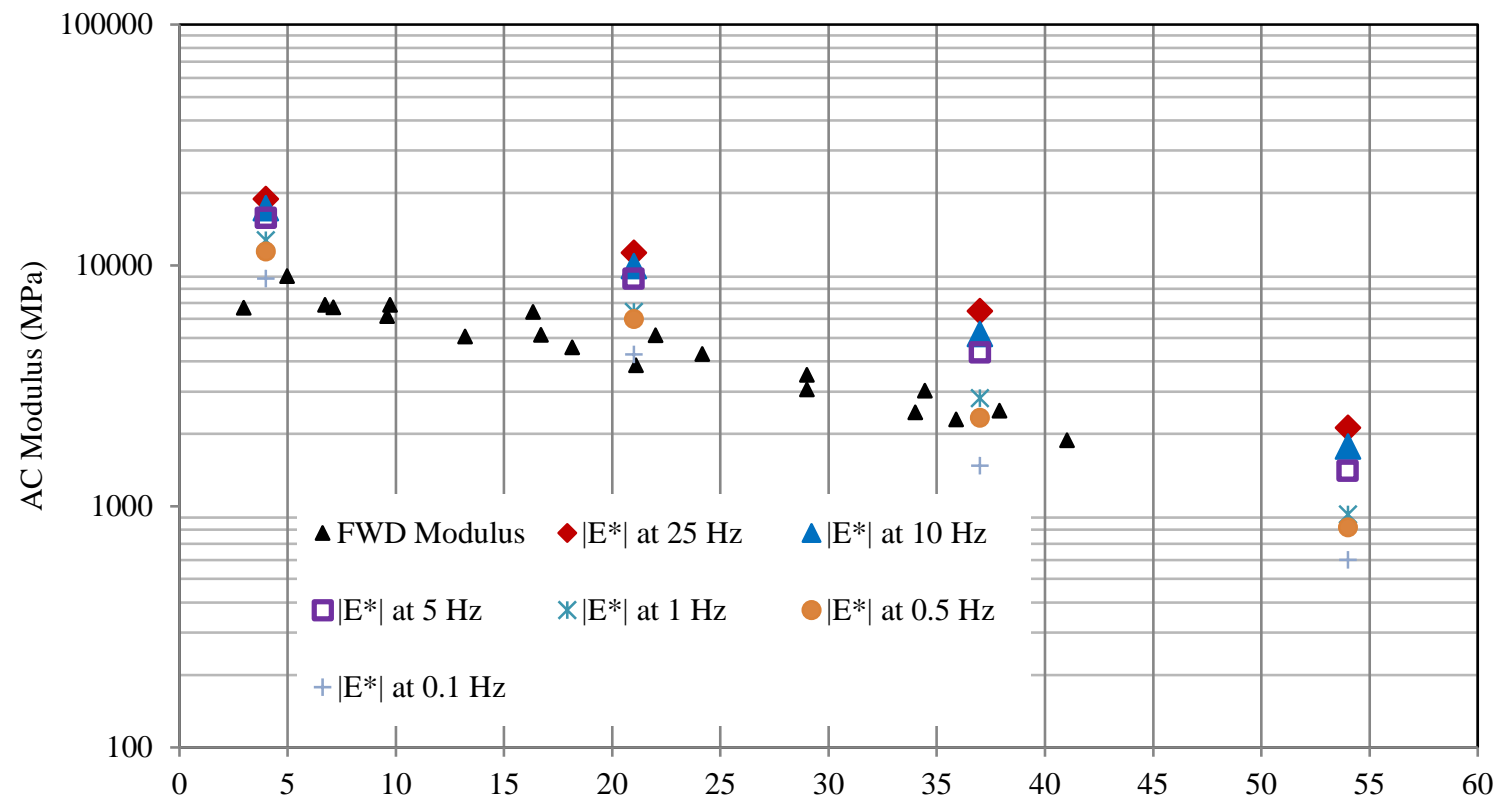

Avg AC Temperature $\left({ }^{\circ} \mathrm{C}\right)$

Figure 11. Backcalculated and laboratory determined moduli.

\section{Conclusions}

This study conducted FWD tests in a single pavement section in New Mexico. Based on the tests on a single pavement, the following conclusions can be made:

a) AC moduli along the wheel path and the middle of the wheel path of this pavement are almost equal.

b) The AC modulus decreases with the application of OGFC as OGFC has smaller modulus than AC. 
c) AC modulus decreases with the age of the pavement due to both traffic-induced damage and environmental factors. AC modulus may increase at the initial stage of pavement (say, 1-2 years); however, it has not been investigated in the current study.

d) The laboratory determined $\left|E^{*}\right|$ at $5 \mathrm{~Hz}$ is 1.7 to 1.9 times the backcalculated AC modulus for the mixture in this study.

\section{Acknowledgements}

This research is funded by the New Mexico Department of Transportation (NMDOT), Grant No. NM11MSC03. The authors would like to appreciate the research funding provided by the New Mexico Department of Transportation (NMDOT). The help of Dr. Timm from NCAT, Auburn University in installing the temperature probes is also acknowledged.

\section{References}

[1] Ahmed MU. Evaluation of FWD software and deflection basin for airport pavements. [M.S. Thesis], Department of Civil Engineering, University of New Mexico, Albuquerque, NM, USA. 2010.

[2] Romanoschi S, Metcalf JB. Simple approach to estimation of pavement structural capacity. Transportation Research Record. 1999;1652(1):198-205.

[3] Rahim A, George K. Falling weight deflectometer for estimating subgrade elastic modulus. Journal of Transportation Engineering. 2003; 129(1): 100-107.

[4] Orr DP. Seasonal variations of in situ materials properties in New York State: FWD testing and data analysis to define seasonal variability. CLRP Report No. 05-01, 2005. Submitted to New York State Department of Transportation.

[5] Islam MR, Ahmed MU, Tarefder RA. Performance evaluation of the embedded sensors in the I-40 Pavement in New Mexico. In: ICSDEC 2012: Developing the Frontier of Sustainable Design, Engineering, and Construction; 2013. p. 519-526.

[6] Appea AK. Validation of FWD testing results at the Virginia Smart Road: theoretically and by instrument response. [Ph.D. dissertation], Blacksburg VA. 2003

[7] Shalaby A, Liske T, Kavussi A. Comparing back-calculated and laboratory resilient moduli of bituminous paving mixtures. Canadian Journal of Civil Engineering. 2004;31(6):988-996.

[8] Oh JH, Fernando EG, Lee SI, Holzschuher C. Correlation of asphalt concrete layer moduli determined from laboratory and nondestructive field tests. Journal of Transportation Engineering. 2012;138(3):361-370.

[9] Hossain M, Scofield L. Correlation between backcalculated and laboratory-determined asphalt concrete moduli. Transportation Research Record. 1992; 1377:67-76

[10] Birgisson B, Roque R, Varadhan A, Thai T, Jaiswal L. Evaluation of thick open graded and bonded friction courses for Florida. Final Report, Project No. 4504968-12 (00026875). Florida Department of Transportation, Tallahassee, FL. 2006.

[11] Williams R, Shaidur R. Premature asphalt concrete pavement cracking. Report No. FHWA-OR-RD-15-16. Oregon Department of Transportation, Research Section, Salem OR. 2015.

[12] Von Quintus HL, Simpson A L. Back-calculation of layer parameters for LTPP test sections, Volume II: Layered elastic analysis for flexible and rigid pavements. Report No. FHWA-RD-01-113. Federal Highway Administration, McLean, Virginia. 2002.

[13] AASHTO T 166-07. Bulk specific gravity of compacted hot mix asphalt using saturated surface-dry specimens. Standard Specifications for Transportation Materials and Methods of Sampling and Testing, American Association of State Highway and Transportation Officials, Washington, DC, 27th Edition; 2007.

[14] AASHTO T 209-05. Theoretical maximum specific gravity and density of hot mix paving mixtures. Standard Specifications for Transportation Materials and Methods of Sampling and Testing. American Association of State Highway and Transportation Officials, Washington, DC, 27th Edition; 2007.

[15] Wang Y, Leng Z, Wang G. Structural contribution of open-graded friction course mixes in mechanisticempirical pavement design. International Journal of Pavement Engineering. 2014;15(8):731-741.

[16] Fernando E, Liu W, Ryu D. Development of a procedure for temperature correction of backcalculated ac modulus. Report No. FHWA/TX-02/1863-1. Texas Department of Transportation, Research and Technology Implementation Office, Austin, Texas. 2001.

[17] Park SW, Kim YR. Temperature correction of backcalculated moduli and deflections using linear viscoelasticity and time-temperature superposition. Transportation Research Record. 1997;1570(1):108-117.

[18] Islam MR, Mannan UA, Rahman AA, Tarefder RA. Effects of reclaimed asphalt pavement on hot-mix asphalt. Advances in Civil Engineering Materials. 2014;3(1):291-307. 
[19] AASHTO PP 62-13. Standard practice for developing dynamic modulus master curves for hot mix asphalt (HMA). Standard Specifications for Transportation Materials and Methods of Sampling and Testing, 2013. American Association of State Highway and Transportation Officials, Washington, D.C. 2013.

[20] Ulloa A, Hajj EY, Siddharthan RV, Sebaaly PE. Equivalent loading frequencies for dynamic analysis of asphalt pavements. Journal of Materials in Civil Engineering. 2013;25(9):1162-1170.

(C) 2019 by the author(s). This work is licensed under a Creative Commons Attribution 4.0 International License (http://creativecommons.org/licenses/by/4.0/). Authors retain copyright of their work, with first publication rights granted to Tech Reviews Ltd. 